\title{
Tuning the Properties of Polyether Alkyl Urea Derivatives as Rheology Modifiers in Cosmetic Solvents
}

\author{
Monissa C. Paderes,* Craig James, Scott A. Jamieson, Anh Hung Mai, Juan Hermoso Limon, \\ Marc Dolatkhani, Susana Fernandez-Prieto, Wim M. De Borggraeve, and Emiliano Fratini
}

\begin{abstract}
Polyether alkyl urea derivatives were synthesized, and their properties as gelators in solvents commonly used in cosmetic formulations such as Labrafac cc, isopropyl myristate, and isododecane were investigated. A solvent-free larger-scale (up to $70 \mathrm{~g}$ ) hydrophobic functionalization of the polyetheramines was carried out by one-step reaction with alkyl or aryl-containing isocyanates, which resulted in the formation of urea-functionalized polyethers. Systematic structural studies were conducted by varying the nature and molecular weight of the polyether backbone and the length of the linker and the side chain. The gels obtained have an appearance varying from opaque to transparent, and their properties were characterized by rheological measurements and small-angle X-ray scattering (SAXS) studies. Rheological analysis indicated the dependence of the gel properties on the hydrophobicity of the alkyl end groups and the type of polyether backbone. SAXS

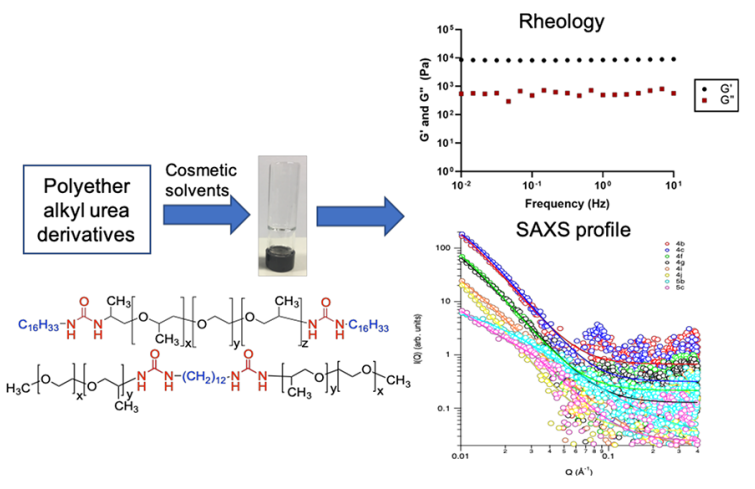
measurements revealed a topological description of the network structures of these materials wherein the gels obtained in Labrafac cc form defined structures from the fiber bundles, while those in isopropyl myristate produce clusters. The results obtained in this study offer potential applications in perfume and cosmetic formulations.
\end{abstract}

KEYWORDS: polyetheramines, polyether alkyl urea, rheology modifier, cosmetic solvents, small-angle X-ray scattering

\section{INTRODUCTION}

The high demand for personal care products has rapidly and continuously increased over the past years. ${ }^{1}$ The fast growth in the consumption of cosmetic products has led to the development and advancement of new and effective ingredients for formulations. Polymeric additives, both synthetic and natural, have been widely utilized in personal care products as emollients, emulsifiers, thickeners, and rheology modifiers. $^{2-5}$ The broad interest in the use of polymers in the product formulations is mainly due to easy manipulation and tailoring of their physical and chemical attributes via modifications such as cross-linking and copolymerization. ${ }^{6}$ The most common examples of bio-based natural polymers used in cosmetic products are chitin, alginates, carrageenan, pectin, and xanthan gums. ${ }^{7-9}$ They serve mainly as emulsifiers, thickeners, emollients, and/or antibacterial agents. ${ }^{10}$ Polyacrylates $^{11}$ and polyurethanes, ${ }^{3}$ on the other hand, are among the most extensively investigated classes of synthetic polymers. Similar to biopolymers, they also function as thickeners, rheology modifiers, emulsifiers, moisturizers, and dispersants ${ }^{3,5,12}$ and are able to facilitate the controlled release of active compounds. ${ }^{2}$ The flexibility in the structural modification of synthetic polymers is one advantage that they have over most natural materials. ${ }^{13}$
Polyetheramines are mono-, di-, or triamine terminated polyether derivatives commercialized under the trademark Jeffamine. ${ }^{14,15}$ Their backbone is generally derived from propylene oxide, ethylene oxide, or a combination of both. Jeffamine polyetheramines have been reported to find wide applications as new materials in many different fields. For instance, they have been used as an epoxy-curing agent, ${ }^{16}$ as additive for industrial and decorative coatings and paints, and as corrosion inhibitor. ${ }^{17-19}$ In addition, chemical modifications of Jeffamine derivatives have enabled tuning of their properties to specific and directed applications. Thermoresponsive hydrogels that are based on chemically modified polyetheramines were reported to have potential applications in drug delivery and biomaterial science. ${ }^{20-24}$ Porous materials that were derived from Jeffamines functionalized with surfactants have been demonstrated to show potential utility in the field of catalysis. $^{25-27}$ Polymeric networks that are Jeffamine and 
Scheme 1. General Scheme for the Lab-Scale Functionalization ${ }^{a}$

A.

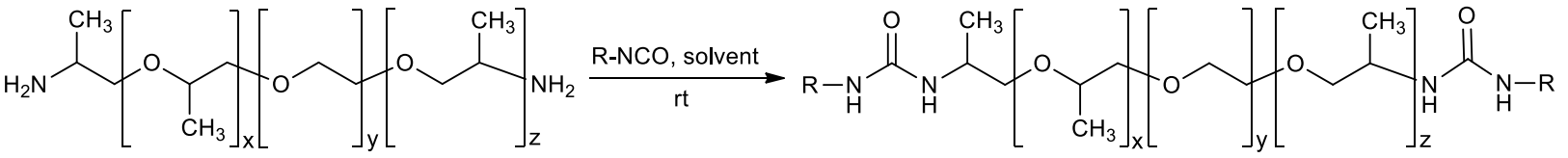

B.

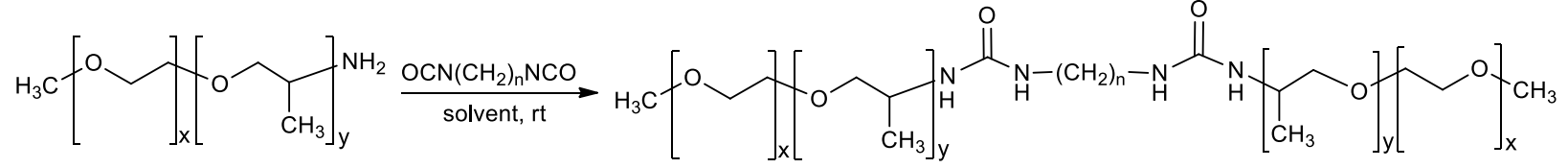

a (A) Polyether bis-amine polymers where $\mathrm{R}=$ alkyl or aryl-containing group. Reaction conditions: polyetheramine (1 equiv) and R-NCO (2.052.1 equiv with respect to amine) in dry solvent $\left(\mathrm{CH}_{2} \mathrm{Cl}_{2}\right.$ or THF), stirred for $16 \mathrm{~h}$ at room temperature under $\mathrm{N}_{2}$ atmosphere. (B) Polyether monoamine with alkyl diisocyanate. Reaction conditions: polyether monoamine (2.05 equiv) and $\mathrm{OCN}\left(\mathrm{CH}_{2}\right)_{n} \mathrm{NCO}(1$ equiv) in dry solvent, stirred for $16 \mathrm{~h}$ at room temperature under $\mathrm{N}_{2}$ atmosphere.

lithium-based were also developed as highly conductive materials. $^{28,29}$ The wide range of molecular weights available as well as the composition of the repeating units of the Jeffamine products make these polymeric materials attractive and advantageous to use.

The personal care market is predominantly driven by skin care products. ${ }^{1}$ Despite some major breakthroughs in the cosmetic industry, there is still a challenge to produce stable products that provide the desired performance. Thus, there remains a continuous need to further develop innovative and high-performing materials which satisfy different product requirements. Therefore, the main objective of this study is to identify polymeric rheology modifiers for solvents that are commonly used in cosmetic formulations. A rheology modifier is an important component of a liquid composition used to modify its flow behavior, provide stability, and improve the aesthetics of the system. $^{30,31}$ The choice of the most effective rheology modifier is dependent on several factors, such as the type of flow needed and the nature and characteristic performance of the formulation.

In this study, it was found that the properties of Jeffamine polymer derivatives can be tuned by introducing hydrophobic functionalities. Our group has successfully transformed these compounds into efficient rheology modifiers for hydrophobic systems such as cosmetic solvents by providing suspension power via gel formation. ${ }^{32}$ In this work, the solvents used for gelation investigation are synthetic oils such as triglycerides (caprylic/capric triglycerides or Labrafac cc), isopropyl myristate, and isododecane (Figure S1, Supporting Information). These are common organic solvents used for a number of beauty products such as creams, cosmetic foundations, and many others because of their availability, low price, and emollient property. ${ }^{33}$ To the best of our knowledge, this is the first report that uses urea-functionalized polyetheramines as a rheology modifier for solvents used in cosmetic formulations.

\section{EXPERIMENTAL SECTION}

General Procedure for the Synthesis of Polyether Alkyl Urea Derivatives. General Experimental Information. All chemicals, reagents, and solvents used for synthesis were purchased from Sigma-Aldrich and used as received. The solvents (Labrafac cc, isopropyl myristate, and isododecane) for gelation studies were used as supplied by PolymerExpert. For lab-scale synthesis: ${ }^{1} \mathrm{H}$ NMR spectra were recorded on a Bruker Avance spectrometer operating at $300 \mathrm{MHz}$. Spectra are reported in parts per million (ppm) relative to residual chloroform $(7.26 \mathrm{ppm})$. A Bruker Vertex 70 spectrometer was used for IR spectroscopic analysis. All the samples were characterized in powder form. The OPUS software package is used to analyze the FTIR spectra. The average and number-average molecular weight $\left(M_{\mathrm{w}}\right.$ and $M_{\mathrm{n}}$, respectively) and the molecular weight distribution (PDI) were determined by gel permeation chromatography (GPC). GPC was performed on a Shimadzu apparatus (UV and $\mathrm{RI}$ detection) with a PLgel D column and THF as the eluent at $303 \mathrm{~K}$ calibrated with linear polystyrene standards.

Lab-Scale Synthesis. Jeffamine and dry solvent $\left(\mathrm{THF}\right.$ or $\left.\mathrm{CH}_{2} \mathrm{Cl}_{2}\right)$ were added to a two-neck $100 \mathrm{~mL}$ round-bottom flask equipped with a magnetic stirrer under $\mathrm{N}_{2}$ atmosphere (balloon). Then, the isocyanate was added at room temperature via an airtight syringe. After the reaction was stirred for $16 \mathrm{~h}$, precipitates were observed, which were filtered off by gravity filtration. The filtrate was dried in vacuo by using a rotary evaporator followed by drying under vacuum to obtain the desired product. The polyether alkyl urea derivative was used without further purification.

Larger-Scale Synthesis. Jeffamine was dried in a $250 \mathrm{~mL}$ threeneck round-bottom flask under vacuum at $80{ }^{\circ} \mathrm{C}$ for $2 \mathrm{~h}$. Then, the isocyanate was added dropwise to the reaction flask (over 1-1.5 h) via an addition funnel while stirring at $80-85{ }^{\circ} \mathrm{C}$ under $\mathrm{N}_{2}$ atmosphere. The reaction was monitored by FTIR spectroscopy. If a small amount of isocyanate still remained after about $2 \mathrm{~h}$ of stirring, a small amount of Jeffamine was slowly added to the reaction mixture until its FTIR spectrum showed no more isocyanate. The reaction was cooled to room temperature. The polyether alkyl urea derivative was used without further purification.

Gelation Studies. Gelation studies were performed using an $8 \mathrm{~mL}$ screw cap glass vial by heating the polyether alkyl urea derivatives to $80{ }^{\circ} \mathrm{C}$ in the desired solvent (Labrafac cc, isopropyl myristate, isododecane) using an oil bath or a heating block. For $5 \mathrm{wt} \%, 50 \mathrm{mg}$ of polyether alkyl urea derivatives was dissolved in $950 \mathrm{mg}$ of solvent. The solution was heated until all the solids were dissolved after which it was cooled to room temperature by quenching with either running water or with a dry ice/acetone solution. Gelation was confirmed by vial inversion. For consistency, the gelation tests were performed initially at $5 \mathrm{wt} \%$. The concentration was further lowered by $0.5 \mathrm{wt} \%$ decrements for those that successfully formed gels to find the minimum gel concentration.

Rheological Characterizations. All rheological measurements were performed using a controlled-stress rheometer, DHR I from TA Instruments. Rheological data were obtained using $40 \mathrm{~mm}$ diameter plate-plate geometry with a $1 \mathrm{~mm}$ gap. To determine the linear viscoelastic (LVE) range and the crossover point of the gels $\left(G^{\prime \prime}>\right.$ $\left.G^{\prime}\right)$, oscillatory amplitude sweep tests $(\gamma=0.1-1000 \%)$ were carried out at a fixed angular frequency of $6.28 \mathrm{rad} / \mathrm{s}$. Samples at a concentration of $3 \mathrm{wt} \%$ in Labrafac cc or isopropyl myristate were prepared approximately $24 \mathrm{~h}$ before the analysis to complete the gelation process. All samples were maintained at $20{ }^{\circ} \mathrm{C}$ for $2 \mathrm{~min}$ before testing. The sample was placed directly onto the surface of the rheometer, and frequency sweep tests were performed between 0.01 and $100 \mathrm{~Hz}$ at a constant strain of $1 \%$. 
Data analysis of the rheological measurements was performed using GraphPad Prism 8 software to obtain the average and standard deviation of two sets of data.

SAXS Measurements. All small-angle scattering measurements were performed using a HECUS S3-Micro system. This Kratky-type camera is equipped with a position-sensitive detector comprising 1024 channels which are $54 \mu \mathrm{m}$ in width. $\mathrm{Cu} \mathrm{K} \alpha$ radiation with a wavelength $(\lambda)$ of $1.542 \AA$ at a power of $50 \mathrm{~W}$ was obtained using an ultrabrilliant point microfocus X-ray source (GENIX-Fox 3D, Xenocs, Grenoble).

A sample-to-detector distance of $281 \mathrm{~mm}$ (calibrated using silver behenate) provided a measurable $q$-range between 0.01 and $0.54 \AA^{-1}$ (where $q$, the scattering vector, is given by $q=4 \pi / \lambda \sin \theta$, and $2 \theta$ is the scattering angle).

Samples at a concentration of $3 \mathrm{wt} \%$ in Labrafac cc or isopropyl myristate were placed into demountable cells containing Kapton film windows giving a sample thickness of $1 \mathrm{~mm}$. Measurements were performed under vacuum to reduce scattering from air and at a temperature of $25^{\circ} \mathrm{C}$. Raw scattering curves were corrected for the scattering of the cell. Data acquisition time was set at $2 \mathrm{~h}$.

\section{RESULTS AND DISCUSSION}

Chemical Modifications of Polyetheramine Derivatives. Two types of hydrophobic modifications were performed on a series of readily available polyetheramines: (1) grafting of alkyl and aryl-containing urea groups at the $\mathrm{N}$ terminus of the polyetheramines (Scheme 1A) and (2) coupling of polyether monoamines with alkyl and arylcontaining diisocyanates (Scheme 1B). The first type of chemical modification was easily accomplished in one step via treatment of polyetheramines with alkyl or aryl-containing isocyanates using anhydrous $\mathrm{CH}_{2} \mathrm{Cl}_{2}$ or THF as solvent under inert conditions, resulting in the formation of alkyl/aryl urea polyether derivatives. Scheme $1 \mathrm{~A}$ shows the general procedure for the functionalization of polyether bis-amine compounds. A similar procedure was followed for the modification of monoand triamine polyethers.

The other type of modification was performed by the reaction of polyether monoamine with alkyl and arylcontaining diisocyanates as shown in Scheme 1B. The reaction was also performed under inert conditions using dry $\mathrm{CH}_{2} \mathrm{Cl}_{2}$ or THF as the solvent. Using ${ }^{1} \mathrm{H}$ NMR, FTIR spectroscopy, and GPC, successful functionalization of the polyetheramines was confirmed. The $M_{\mathrm{n}}, M_{\mathrm{w}}$, and PDI of the functionalized polymers were determined using GPC (Supporting Information, section III). The PDI values obtained range from 1.0 to 1.09 .

Gelation Studies. Gelation studies commenced with the chemically modified poly(ethylene glycol) (PEG) alkyl bisurea $\mathbf{1 a}-\mathbf{d}$ and $\mathbf{2 a}-\mathbf{e}$ (Table 1 ). The solvents used for gelation tests were Labrafac cc, isopropyl myristate, and isododecane, which are good model systems for formulations used in commercial cosmetic products. ${ }^{33}$ The results showed that this type of modified polymer is an effective gelator for Labrafac cc when the $M_{\mathrm{w}}$ of the starting PEG bis-amine polymer is low $\left(M_{\mathrm{w}} \approx 1500\right.$, see entries $\left.2-4\right)$. It is also apparent that increasing the length of the aliphatic side chain (i.e., from C6 to C12) improves the gelation ability of the modified polymers (compare entry 1 to entries 2-4). This result is consistent with polymers that serve as associative thickeners, wherein this effect is thought to be due to the ability of longer alkyl groups to form a network as well as the hydrodynamic radius of the chains. ${ }^{34}$ The effect of increasing the molecular weight of the starting polymer backbone was also investigated. Unfortunately, the modified poly(ethylene glycol) (PEG) alkyl bis-urea
Table 1. Gelation Studies of PEG Alkyl Bis-urea Compounds

$$
\begin{array}{ll}
{ }^{\mathrm{a}} M_{W}=1500 & { }_{M}=3400 \\
\text { 1a: } \mathrm{R}=\mathrm{C}_{6} \mathrm{H}_{13} & \text { 2a: } \mathrm{R}=\mathrm{C}_{12} \mathrm{H}_{25} \\
\text { 1b: } \mathrm{R}=\mathrm{C}_{12} \mathrm{H}_{25} & \text { 2b: } \mathrm{R}=\mathrm{C}_{16} \mathrm{H}_{33} \\
\text { 1c: } \mathrm{R}=\mathrm{C}_{16} \mathrm{H}_{33} & \text { 2c: } \mathrm{R}=\mathrm{C}_{18} \mathrm{H}_{37} \\
\text { 1d: } \mathrm{R}=\mathrm{C}_{18} \mathrm{H}_{37} & { }^{\mathrm{a}} M_{w}=6000 \\
& \text { 2d: } \mathrm{R}=\mathrm{C}_{12} \mathrm{H}_{25} \\
& \mathbf{2 e :} \mathrm{R}=\mathrm{C}_{16} \mathrm{H}_{33}
\end{array}
$$

$\begin{array}{ccccc}\text { entry }^{b} & \text { gelator } & \text { Labrafac cc } & \text { isopropyl myristate } & \text { isododecane } \\ 1 & \text { 1a } & \text { P } & \text { P } & \text { I } \\ 2 & \text { 1b } & \text { G }(2.0) & \text { P } & \text { I } \\ 3 & \text { 1c } & \text { G }(2.0) & \text { P } & \text { I } \\ 4 & \text { 1d } & \text { G }(2.0) & \text { P } & \text { I } \\ 5 & \text { 2a } & \text { P } & \text { P } & \text { I } \\ 6 & \text { 2b } & \text { P } & \text { P } & \text { I } \\ 7 & \text { 2c } & \text { P } & \text { P } & \text { I } \\ 8 & \text { 2d } & \text { P } & \text { P } & \text { I } \\ 9 & \text { 2e } & \text { P } & \text { P } & \text { I }\end{array}$

${ }^{a} M_{\mathrm{w}}$ (Da) refers to the average molecular weight of the starting polyetheramine. ${ }^{b}$ Gelation tests were performed at $5 \mathrm{wt} \%$. P, precipitates upon cooling; G, gel; I, insoluble; number in parentheses is the minimum concentration in wt \% at which a gel is formed.

2a-e $\left(M_{w}>3000\right.$, entries 5-9) failed to form a gel in Labrafac cc under analogous conditions. These modified polymers were also found to form a precipitate in isopropyl myristate when cooled to room temperature and were insoluble in isodecane, even when heated to higher temperature.

These studies revealed that at concentrations $>3$ wt $\%$, compounds $\mathbf{1} \mathbf{b}-\mathbf{d}$ formed gels in Labrafac cc that are stable for more than 1 week. Stable gels are those that did not show precipitation or phase separation and did not flow upon vial inversion. In addition, they have successfully formed gels at 2 wt \% (Table 1, entries 2-4); however, they exhibit vial inversion stability of less than a week (2-3 days). These results prompted us to further investigate other polymer backbones.

Another polymer backbone that was examined is the diamine terminated poly(propylene glycol) (PPG) marketed as Jeffamine D. The gelation test results using the modified PPG alkyl bis-urea $\mathbf{3 a - d}$ were disappointing, as they failed to form gels in any of the solvents tested (Table 2). The incorporation of the methyl substituents in the polymer backbone increases the solubility of the functionalized polyether alkyl bis-urea.

The importance of the nature of the polymer backbone was further assessed by studying the Jeffamine ED polymers. These are polyether diamine derivatives composed of mixtures of PEG and PPG. The hydrophobically modified Jeffamine ED alkyl bis-urea compounds proved to be highly effective gelators of Labrafac cc and isopropyl myristate (Table 3). These compounds displayed a trend similar to the PEG alkyl bis-urea compounds (Table 1) wherein those with longer aliphatic side chains perform better as a gelator than those with shorter chains. The effect of the longer alkyl group is more pronounced for this type of compound as stable gels can be formed at lower concentrations (Table 3, compare entry 1 to entries 2 and 3). Based on the gelation test results, there is no 
Table 2. Gelation Studies of PPG Alkyl Bis-urea Compounds<smiles>[R]NC(=O)NC(C)COCC(C)NC(=O)N[R]</smiles>

\begin{tabular}{ccccc} 
entry $^{b}$ & gelator & Labrafac cc & isopropyl myristate & isododecane \\
\hline 1 & $3 \mathbf{a}$ & $\mathrm{D}$ & $\mathrm{D}$ & $\mathrm{P}$ \\
2 & $3 \mathbf{b}$ & $\mathrm{D}$ & $\mathrm{D}$ & $\mathrm{P}$ \\
3 & $3 \mathbf{c}$ & $\mathrm{D}$ & $\mathrm{D}$ & $\mathrm{P}$ \\
4 & 3d & $\mathrm{D}$ & $\mathrm{D}$ & $\mathrm{P}$ \\
\hline
\end{tabular}

${ }^{a} M_{\mathrm{w}}$ (Da) refers to the average molecular weight of the starting polyetheramine. ${ }^{b}$ Gelation tests were performed at $5 \mathrm{wt} \%$. D, stays dissolved even after cooling; P, precipitates upon cooling.

Table 3. Gelation Studies of Jeffamine ED Alkyl/Aryl Bisurea Compounds

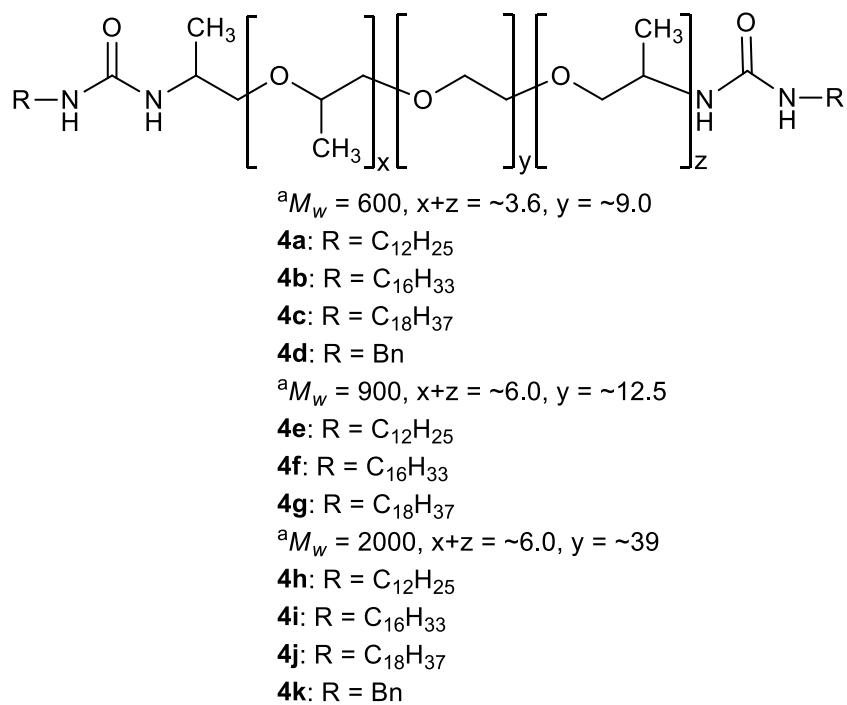

\begin{tabular}{ccccc} 
entry $^{b}$ & gelator & Labrafac cc & isopropyl myristate & isododecane \\
\hline 1 & $\mathbf{4 a}$ & $\mathrm{G}(2.0)$ & $\mathrm{G}(3.0)$ & $\mathrm{P}$ \\
2 & $\mathbf{4 b}$ & $\mathrm{G}(1.5)$ & $\mathrm{G}(2.0)$ & $\mathrm{P}$ \\
3 & $\mathbf{4 c}$ & $\mathrm{G}(1.5)$ & $\mathrm{G}(2.0)$ & $\mathrm{P}$ \\
4 & $\mathbf{4 d}$ & $\mathrm{D}$ & $\mathrm{D}$ & $\mathrm{P}$ \\
5 & $\mathbf{4 e}$ & $\mathrm{G}(3.0)$ & $\mathrm{G}(3.0)$ & $\mathrm{P}$ \\
6 & $\mathbf{4 f}$ & $\mathrm{G}(1.5)$ & $\mathrm{G}(2.0)$ & $\mathrm{P}$ \\
7 & $\mathbf{4 g}$ & $\mathrm{G}(1.5)$ & $\mathrm{G}(2.0)$ & $\mathrm{P}$ \\
8 & $\mathbf{4 h}$ & $\mathrm{P}$ & $\mathrm{P}$ & $\mathrm{P}$ \\
9 & $\mathbf{4 i}$ & $\mathrm{G}(2.0)$ & $\mathrm{G}(2.0)$ & $\mathrm{P}$ \\
10 & $\mathbf{4 j}$ & $\mathrm{G}(2.0)$ & $\mathrm{G}(2.0)$ & $\mathrm{P}$ \\
11 & $\mathbf{4 k}$ & $\mathrm{P}$ & $\mathrm{P}$ & $\mathrm{P}$
\end{tabular}

${ }^{a} M_{\mathrm{w}}$ (Da) refers to the average molecular weight of the starting polyetheramine. ${ }^{b}$ Gelation tests were performed at $5 \mathrm{wt} \%$. G, gel; P, precipitates upon cooling; D, stays dissolved even after cooling; number in parentheses is the minimum concentration in wt \% that a gel is formed.

obvious change on the behavior of compounds with $\mathrm{R}=$ $\mathrm{C}_{16} \mathrm{H}_{33}$ and $\mathrm{C}_{18} \mathrm{H}_{37}$ alkyl side chains, both in Labrafac cc and isopropyl myristate, which was also supported by rheological analysis (vide infra). Generally, the gels formed at the minimum concentration exhibit a vial inversion stability greater than 1 month.

In contrast, when aryl-containing group $(\mathrm{R}=$ benzyl $(\mathrm{Bn}))$ was incorporated with Jeffamine ED polymers (compounds $4 d$ and $4 \mathbf{k}$ ), either dissolution or precipitation occurs in the solvents tested (entries 4 and 11). These compounds were also found to be ineffective gelators of isododecane.

Next, we investigated the use of Jeffamine T series, which are branched polymers (Table 4). As expected, the low- $M_{w}$

Table 4. Gelation Studies of Jeffamine T Alkyl Tris-urea Compounds

$$
\begin{aligned}
& \text { (N) } \\
& { }^{\mathrm{a}} M_{\mathrm{w}}=440, \mathrm{x}+\mathrm{y}+\mathrm{z}=5-6 \\
& \text { 5a: } \mathrm{R}=\mathrm{C}_{12} \mathrm{H}_{25} \\
& \text { 5b: } \mathrm{R}=\mathrm{C}_{16} \mathrm{H}_{33} \\
& \text { 5c: } \mathrm{R}=\mathrm{C}_{18} \mathrm{H}_{37} \\
& { }^{\mathrm{a}} M_{w}=5000, \mathrm{x}+\mathrm{y}+\mathrm{z}=85 \\
& \text { 5d: } \mathrm{R}=\mathrm{C}_{16} \mathrm{H}_{33} \\
& \text { 5e: } \mathrm{R}=\mathrm{C}_{18} \mathrm{H}_{37}
\end{aligned}
$$

$\begin{array}{ccccc}\text { entry }^{b} & \text { gelator } & \text { Labrafac cc } & \text { isopropyl myristate } & \text { isododecane } \\ 1 & \text { 5a } & \text { G }(3.0) & \text { G }(4.0) & \text { P } \\ 2 & \text { 5b } & \text { G }(2.0) & \text { G }(2.0) & \text { P } \\ 3 & \text { 5c } & \text { G }(2.0) & \text { G }(2.0) & \text { P } \\ 4 & \text { 5d } & \text { V } & \text { P } & \text { P } \\ 5 & \text { 5e } & \text { V } & \text { P } & \text { P }\end{array}$

${ }^{a} M_{\mathrm{w}}$ (Da) refers to the average molecular weight of the starting polyetheramine. ${ }^{b}$ Gelation tests were performed at 1 and $5 \mathrm{wt} \%$. V, viscous; P, precipitates upon cooling; G, gel; number in parentheses is the minimum concentration in wt \% that a gel is formed.

modified polymers were more efficient in gelling both Labrafac cc and isopropyl myristate (entries $1-3$ ). The high- $M_{\mathrm{w}}$ modified compounds were observed to cause an increase in the viscosity of Labrafac cc solution (entries 4-5) by visual inspection. These compounds are also not compatible with isododecane, forming a precipitate in this solvent.

Generally, these polyether alkyl urea derivatives afford gels that are opaque. Representative examples of the gels prepared in $5 \mathrm{~g}$ scale are shown in Figure 1A.

Table 5 shows the gelation test results for Jeffamine $\mathrm{M}$ alkyl monourea compounds. Only compound $\mathbf{6 b}$ formed a weak gel in Labrafac cc at $5 \mathrm{wt} \%$. Although we cannot directly compare these results with the modified polyether alkyl bis- and trisurea compounds because the polymer composition and $M_{\mathrm{w}}$ are not entirely the same, it can be concluded that the former showed superior gelation behavior over the monourea compounds based on the gelation test results.

The polyether bis-urea compounds shown in Table 6 were functionalized by coupling of diisocyanates with Jeffamine $M$ polymers. Similar trends were observed wherein those compounds with low $M_{\mathrm{w}}$ polymer backbone and longer alkyl 
A.

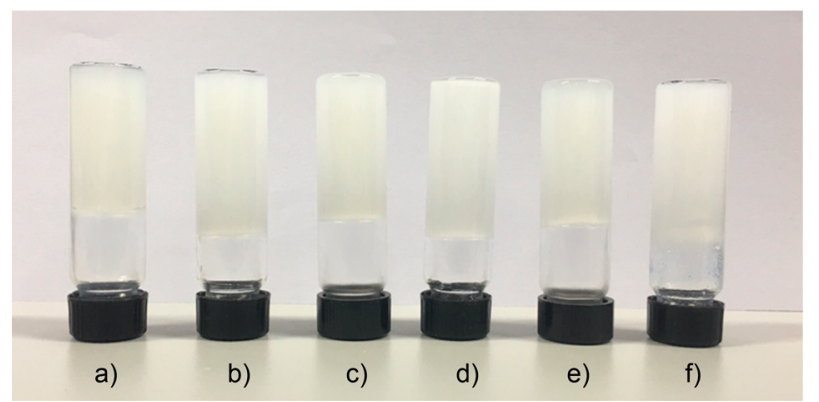

B.

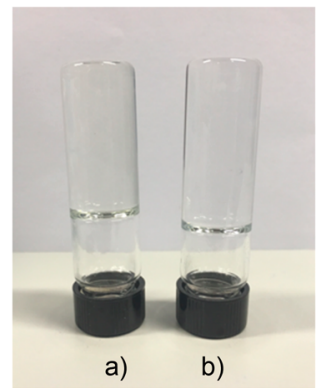

Figure 1. (A) Examples of gels formed in Labrafac cc (a) $4 c$, (c) $4 \mathbf{j}$, and (e) $5 c$ and in isopropyl myristate (b) $4 c$, (d) $4 \mathbf{j}$, and (f) $5 c$ at 3 wt \%. (B) Transparent gels formed from $7 \mathbf{b}$ in (a) Labrafac cc and (b) isopropyl myristate at $3 \mathrm{wt} \%$.

Table 5. Gelation Studies of Jeffamine M Alkyl Urea Compounds<smiles>[R]NC(=O)NC(C)COC(C)(C)COC(C)(C)C</smiles>

6a: ${ }^{a} M_{w}=600, x=1, y=9, R=C_{12} \mathrm{H}_{25}$

6b: ${ }^{\mathrm{a}} M_{w}=1000, \mathrm{x}=19, \mathrm{y}=3, \mathrm{R}=\mathrm{C}_{12} \mathrm{H}_{25}$

$\begin{array}{ccccc}\text { entry }^{b} & \text { gelator } & \text { Labrafac cc } & \text { isopropyl myristate } & \text { isododecane } \\ 1 & \mathbf{6 a} & \mathrm{D} & \mathrm{D} & \mathrm{P} \\ 2 & \mathbf{6 b} & \mathrm{G} & \mathrm{P} & \mathrm{P}\end{array}$

${ }^{a} M_{\mathrm{w}}$ (Da) refers to the average molecular weight of the starting polyetheramine. ${ }^{b}$ Gelation tests were performed at $5 \mathrm{wt} \%$. G, gel; D, stays dissolved even after cooling; P, precipitates upon cooling.

chain work better in Labrafac cc and isopropyl myristate (entries 1 and 2). In addition, the aryl-containing substituent, i.e., compound $7 \mathrm{c}$, is detrimental to the gelating ability, as it failed to form gel in isododecane and precipitated upon cooling (entry 3). Interestingly, the gels formed using these compounds are transparent, one important quality of a commercial cosmetic product. Figure 1B shows examples of transparent gels formed in Labrafac cc and isopropyl myristate.
Rheological Characterizations. Rheological analyses were conducted to gain further insights on the properties of the gels. The rheological parameters of the frequency sweep tests in the LVE region of the polyether alkyl urea compounds in Labrafac cc and isopropyl myristate at 3 wt $\%$ are summarized in Table 7 , and the rheology plots are shown in

Table 7. Rheology Data of Gels Obtained in Labrafac cc and Isopropyl Myristate at 3 wt \%

\begin{tabular}{cccccccc} 
& \multicolumn{3}{c}{ Labrafac cc gelator $^{a}$} & & \multicolumn{3}{c}{ isopropyl myristate } \\
\cline { 2 - 4 } \cline { 6 - 7 } $\mathbf{4 b}$ & $G^{\prime}(\mathrm{Pa})$ & $G^{\prime \prime}(\mathrm{Pa})$ & $\tan \delta$ & & $G^{\prime}(\mathrm{Pa})$ & $G^{\prime \prime}(\mathrm{Pa})$ & $\tan \delta$ \\
$\mathbf{4}$ & 8483 & 496 & 0.058 & & 418 & 36 & 0.086 \\
$\mathbf{4}$ & 8384 & 743 & 0.089 & & & & \\
$\mathbf{4}$ & 6682 & 506 & 0.076 & & & \\
$\mathbf{4}$ & & & & & 1955 & 202 & 0.103 \\
$\mathbf{4}$ & 2905 & 217 & 0.075 & & & \\
$\mathbf{5 b}$ & 549 & 45 & 0.082 & & 2470 & 240 & 0.097 \\
$\mathbf{5 c}$ & 622 & 37 & 0.059 & & & \\
$\mathbf{7 b}$ & 413 & 86 & 0.208 & 129 & 16 & 0.124 \\
${ }^{a}$ Values of $G^{\prime}$ and $G^{\prime \prime}$ & were taken at a frequency equal to $1 \mathrm{~Hz}$.
\end{tabular}

Figures S12-S14 (Supporting Information). The data reported are the average of two independent measurements of the

Table 6. Gelation Studies of Jeffamine M Alkyl/Aryl Bis-urea Compounds

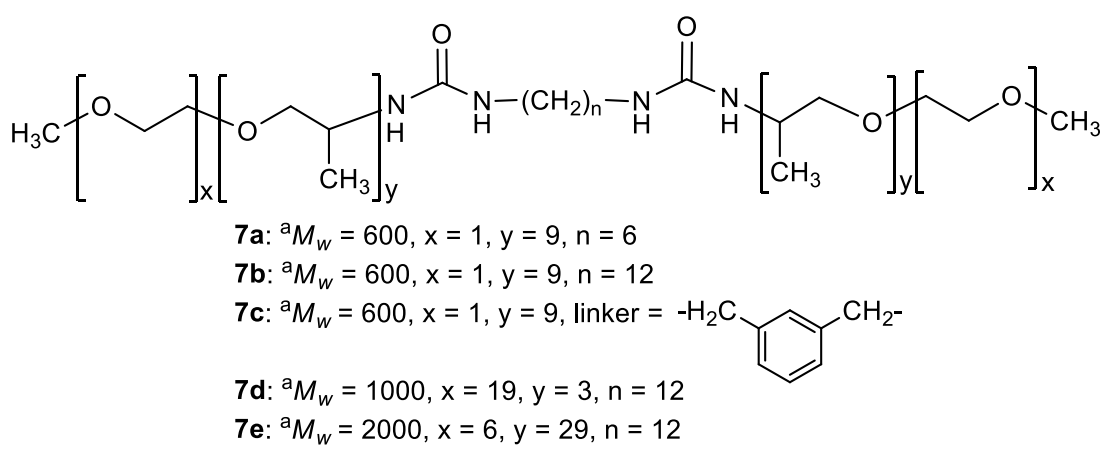

$\begin{array}{ccccc}\text { entry }^{b} & \text { gelator } & \text { Labrafac cc } & \text { isopropyl myristate } & \text { isododecane } \\ 1 & 7 \mathbf{a} & \mathrm{G}(3.0) & \mathrm{G}(4.0) & \mathrm{P} \\ 2 & 7 \mathbf{b} & \mathrm{G}(1.5) & \mathrm{G}(1.0) & \mathrm{P} \\ 3 & 7 \mathbf{c} & \mathrm{D} & \mathrm{D} & \mathrm{P} \\ 4 & 7 \mathbf{d} & \mathrm{D} & \mathrm{D} & \mathrm{P} \\ 5 & 7 \mathbf{e} & \mathrm{D} & \mathrm{D} & \mathrm{P} \\ \mathrm{P}\end{array}$

${ }^{a} M_{\mathrm{w}}$ (Da) refers to the average molecular weight of the starting polyetheramine. ${ }^{b}$ Gelation tests were performed at 5 wt $\%$. G, gel; D, stays dissolved even after cooling; P, precipitates upon cooling; number in parentheses is the minimum concentration in wt \% that a gel is formed. 
storage $\left(G^{\prime}\right)$ and loss $\left(G^{\prime \prime}\right)$ moduli (Tables S1 and S2, Supporting Information).

All the gels tested in both solvents showed similar rheological profiles, wherein the storage modulus $\left(G^{\prime}\right)$ is greater than the loss modulus $\left(G^{\prime \prime}\right)$ throughout the LVE region, demonstrating a solid-like behavior (Table 7$)$. This produces small values of loss factor, defined as $\tan \delta(\tan \delta=$ $\left.G^{\prime \prime} / G^{\prime}\right)$, and represents the physical behavior of the gels. The $\tan \delta$ is less than 1 for all samples, which suggests the elastic nature of the gels. In Labrafac cc, the gels of $4 b$ and $4 c$ exhibited the highest $G^{\prime}$ value $(\sim 8400 \mathrm{~Pa})$, indicative of the formation of physically robust gels, whereas the smallest value observed was from $7 \mathbf{b}$ with less than $500 \mathrm{~Pa}$. The long aliphatic groups, $\mathrm{C}_{16} \mathrm{H}_{33}$ and $\mathrm{C}_{18} \mathrm{H}_{37}$, did not show significant effect on the rheological properties of the polyether alkyl urea compounds as evidenced by the comparable moduli values $\left(G^{\prime}\right.$ and $\left.G^{\prime \prime}\right)$ obtained, i.e., for compounds $4 \mathbf{b}$ and $4 \mathbf{c}, 5 \mathbf{b}$ and 5c. Gels obtained from compounds 5 generally exhibit moduli values less than those from 4 , indicating that linear polymer backbone is favored over branched.

Similarly, gels obtained in isopropyl myristate also exhibit viscoelasticity (Table 7). Noteworthy is that the gel formed from the branched polyether showed higher $G^{\prime}$ values in isopropyl myristate than Labrafac cc.

Small-Angle X-ray Scattering. Scattering studies were conducted to gain a better understanding of the network formation and structure for the functionalized polyetheramines and how the $M_{\mathrm{w}}$ and nature of the polymer backbone might affect the morphology and dimensions at the nanoscale. Gels formed in both Labrafac cc and isopropyl myristate were examined to identify any differences due to the choice of solvent. The samples included in the SAXS studies are $\mathbf{4 b}, \mathbf{c}$, $\mathbf{4 f}, \mathbf{g}, \mathbf{4 i}, \mathbf{j}$, and $\mathbf{5 b}, \mathbf{c}$. Representative examples of SAXS profiles are shown in Figure S15 (Supporting Information).

SAXS data were modeled using a correlation length model comprising a modified Lorenztian term to account for scattering arising from a polymer network. This network is characterized by a correlation length that described the socalled "blob" size (comparable to the network mesh size) as seen in semidilute polymer and gel systems (eq 1). ${ }^{35}$

$$
I(Q)=\frac{I_{L}(0)}{\left[1+(Q \xi)^{m}\right]}+b k g
$$

$\xi$ is the correlation length describing the blob size, and $I_{\mathrm{L}}(0)$ is the network scattering intensity at $q=0$. The Lorenztian exponent, $m$, describes the fractal dimension of the scattering object. A Lorenztian exponent equal to 2 describes an overlapping polymer chains in a semidilute system, i.e., coillike, while a value of 3 shows a more defined although fuzzy interface; 4 shows the maximum allowed for this model for a well-defined smooth interface, i.e., a globular structure. ${ }^{36}$

The model fitting for the scattering provides information about the polymer interface for the fibers in the network. Based on the values obtained from the model (Table 8), it can be assumed that the network is highly disordered and is not affected by a linear scaling of molecular size or solvent type. For the gels formed in Labrafac cc, the Lorentzian exponent is close to or equal to 4, suggesting that there are defined structures present in the short-range system. In contrast, the gels formed in isopropyl myristate show a range of values from 2 to 4 for the Lorentzian exponent. The network structures found in the gels formed in isopropyl myristate are less
Table 8. Correlation Length, $\xi(\AA)$, and Lorentzian Exponent, $m$, of Functionalized Polyetheramines

\begin{tabular}{cccccc} 
& \multicolumn{2}{c}{ Labrafac cc } & & \multicolumn{2}{c}{ isopropyl myristate } \\
\cline { 2 - 3 } \cline { 5 - 6 } gelator $^{a}$ & $\begin{array}{c}\text { correlation } \\
\text { length, } \xi \\
{[ \pm 2 \AA]}\end{array}$ & $\begin{array}{c}\text { Lorentzian } \\
\text { exponent, } m\end{array}$ & & $\begin{array}{c}\text { correlation } \\
\text { length, } \boldsymbol{\xi} \\
{[ \pm 2 \AA]}\end{array}$ & $\begin{array}{c}\text { Lorentzian } \\
\text { exponent, } m\end{array}$ \\
4b & 44.3 & 4 & & 52.6 & 2 \\
$\mathbf{4}$ & 113 & 3.7 & & 87.4 & 3.1 \\
$\mathbf{4 f}$ & 39.4 & 4 & & 72.2 & 4 \\
$\mathbf{4 g}$ & 73.6 & 3.3 & & 88.1 & 2.3 \\
$\mathbf{4 i}$ & 42.5 & 3.5 & & 103 & 3 \\
$\mathbf{4 j}$ & 23.4 & 4 & & 10.7 & 3.6 \\
$\mathbf{5 b}$ & 38.1 & 4 & 53.1 & 3.6 \\
$\mathbf{5 c}$ & 41.1 & 4 & 23.7 & 4
\end{tabular}

${ }^{a}$ All calculations performed in IGOR Pro using NIST package for data reduction and analysis. ${ }^{37}$

consistent and more variable in morphology compared to those in Labrafac cc.

The model fitted to the SAXS curves obtained for the gels in this study defines the correlation length, $\xi$ (Table 8), which is a measure of the average spacing between phase regions, assuming smooth interfaces between the phases. In these systems, the correlation length can be considered as the average size of the mesh with respect to $M_{\mathrm{w}}$ of the polymer. The results from the modeling of compounds 4 did not suggest a relationship between the $M_{\mathrm{w}}$ of the polymer and the correlation length, with the highest values achieved for $4 \mathrm{c}$ in Labrafac cc and $\mathbf{4 i}$ in isopropyl myristate. The majority of the gels showed a higher $\xi$ value in isopropyl myristate; however, the similarity between each solvent suggests that there is no defined connection between the molecular weight and correlation length.

Scale-up Synthesis of Modified Polyetheramines. Lab-scale functionalization of the Jeffamine derivatives involves the use of an anhydrous solvent (e.g., dichloromethane, THF). With large-scale synthesis, the use of these solvents is not desirable for a number of reasons: (a) low mass transfer (low concentration of reaction medium, approximately $5 \mathrm{wt} \%$ ); (b) toxicity (e.g., dichloromethane is suspected of causing cancer); (c) cost efficiency (expensive anhydrous solvent and requires extra workup); (d) possible side products. Therefore, synthesis of several promising compounds which possess highly interesting gelating properties (e.g., $4 \mathbf{c}$ and $\mathbf{5 c}$ ) were optimized at large scale (up to $70 \mathrm{~g}$ ) in which solvent-free conditions were applied. By taking advantage of the high reactivities of the isocyanate and primary amine, the reactions were performed in which the Jeffamine derivatives acted as both reactant and solvent. The reactions were carried out in a short period of time $(2-3 \mathrm{~h})$ at a temperature higher than the melting point of the products (e.g., $80{ }^{\circ} \mathrm{C}$ ). Prolonging the reaction time leads to the formation of a product with a darker color. The products obtained using this protocol have rheological properties comparable to those prepared using the conventional lab-scale synthesis.

\section{CONCLUSIONS}

New polyether alkyl urea derivatives were readily synthesized in large scale. These polymeric materials were identified to be effective structurants for cosmetic solvents such as Labrafac cc and isopropyl myristate. The properties of these compounds are found to be dependent on the $M_{\mathrm{w}}$ and the nature of the 
polymer as well as the length of the alkyl groups. Generally, for the modified polyether bis- and tris-urea compounds (e.g., $\mathbf{4 b}$ and $\mathbf{5 b}$, respectively), a $M_{\mathrm{w}}$ of the starting polymer backbone with $<2000 \mathrm{Da}$ exhibits the best rheological properties. It is also clear that the elasticity of the gels is highly dependent on the chain length of the end groups. By increasing the alkyl side chain from 6 to 16 or 18 carbons, the gelating ability of these compounds significantly improves. Rheological analysis showed that in Labrafac cc, the modified compounds with the Jeffamine ED series $\left(M_{\mathrm{w}} \approx 1000-3000 \mathrm{Da}\right)$, a linear polymer backbone showed the highest viscoelastic moduli (i.e., 4b, $\left.G^{\prime}=8483 \mathrm{~Pa}, G^{\prime \prime}=496 \mathrm{~Pa}\right)$. However, in isopropyl myristate, both linear and branched polymer backbones (i.e., Jeffamine T-403) can be effective gelators. Unfortunately, none of the modified polymers form a gel in isododecane. Furthermore, a change in physical appearance of the gels was observed, from opaque to transparent, when the hydrophobic alkyl group is at the center of the polymeric material (i.e., $7 \mathbf{b}$ ). From SAXS measurements, a clear connection between the $M_{w}$ of compounds $\mathbf{4}$ and the correlation length was not observed. However, the Lorenztian exponent suggests the formation of defined structures from the fiber bundles in Labrafac cc and a more variable network formation in isopropyl myristate. Currently, the focus of this research is exploring the potential application of these compounds to commercial perfume and cosmetic formulations. These materials could provide an interesting and more affordable alternative to commercial skin care products. The straightforward, solvent-free, and industrially scalable synthesis together with the viscoelastic properties of these compounds make them good candidates as rheology modifiers for formulations in the cosmetics market.

\section{ASSOCIATED CONTENT}

\section{SI Supporting Information}

The Supporting Information is available free of charge at https://pubs.acs.org/doi/10.1021/acsapm.0c00416.

Representative examples of synthesis of polyether alkyl urea derivatives and their characterization, supplementary data on rheology, and SAXS (PDF)

\section{AUTHOR INFORMATION}

\section{Corresponding Author}

Monissa C. Paderes - Department of Chemistry, Division of Molecular Design and Synthesis, KU Leuven, 3001 Leuven, Belgium; Institute of Chemistry, University of the Philippines Diliman, Quezon City 1101, Philippines; - orcid.org/00000002-4042-4153; Email: mcpaderes1@up.edu.ph

\section{Authors}

Craig James - Department of Chemistry and CSGI, University of Florence, 50019 Sesto Fiorentino Florence, Italy

Scott A. Jamieson - Department of Chemistry and CSGI, University of Florence, 50019 Sesto Fiorentino Florence, Italy

Anh Hung Mai - PolymerExpert, 33600 Pessac, France

Juan Hermoso Limon - Procter \& Gamble, 1853 StrombeekBever, Belgium

Marc Dolatkhani - PolymerExpert, 33600 Pessac, France

Susana Fernandez-Prieto - Procter \& Gamble, 1853 Strombeek-Bever, Belgium

Wim M. De Borggraeve - Department of Chemistry, Division of Molecular Design and Synthesis, KU Leuven, 3001 Leuven,

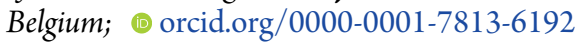

Emiliano Fratini - Department of Chemistry and CSGI, University of Florence, 50019 Sesto Fiorentino Florence, Italy; (1) orcid.org/0000-0001-7104-6530

\section{Notes}

The authors declare no competing financial interest.

\section{ACKNOWLEDGMENTS}

The authors gratefully acknowledge the financial support of the research project ISSFLOW-PIAAP-GA-2013-612330 sponsored by the FP7-PEOPLE-2013-IAPP UE Programme and the UP System Balik PhD Program (OVPAA-BPhd-2017-05).

\section{REFERENCES}

(1) Owh, C.; Chee, P. L.; Loh, X. J. A Global Analysis of the Personal Care Market. In Polymers for Personal Care Products and Cosmetics; Loh, X. J., Ed.; Royal Society of Chemistry: Cambridge, U.K., 2016; pp 1-17.

(2) Lochhead, R. Y. The Role of Polymers in Cosmetics: Recent Trends. In Cosmetic Nanotechnology; ACS Symposium Series; American Chemical Society, 2007; Vol. 961, pp 3-56.

(3) Patil, A.; Ferritto, M. S. Polymers for Personal Care and Cosmetics: Overview. In Polymers for Personal Care and Cosmetics; ACS Symposium Series; American Chemical Society, 2013; Vol. 1148, pp 3-11.

(4) Schulz, D. N.; Glass, J. E. Polymers as Rheology Modifiers; ACS Symposium Series; American Chemical Society, 1991; Vol. 462, pp $2-17$.

(5) Lochhead, R. Y. The Use of Polymers in Cosmetic Products. In Cosmetic Science and Technology; Sakamoto, K., Lochhead, R. Y., Maibach, H. I., Yamashita, Y., Eds.; Elsevier: Amsterdam, 2017; pp 171-221.

(6) Patil, A.; Sandewicz, R. W. Cosmetic Science and Polymer Chemistry: Perfect Together. In Polymers for Personal Care and Cosmetics; ACS Symposium Series; American Chemical Society, 2013; Vol. 1148, pp 13-37.

(7) Yin, X. L.; Loh, X. J. Polymers for Personal Care - Natural Protein-Based Polymers. In Polymers for Personal Care Products and Cosmetics; Loh, X. J., Ed.; Royal Society of Chemistry: Cambridge, U.K., 2016; pp 18-36.

(8) Zheng, Y. J.; Loh, X. J. Natural Rheological Modifiers for Personal Care. In Polymers for Personal Care Products and Cosmetics; Loh, X. J., Ed.; Royal Society of Chemistry: Cambridge, U.K., 2016; pp 60-89.

(9) Chan, S. Y.; Choo, W. S.; Young, D. J.; Loh, X. J. Pectin as a Rheology Modifier: Recent Reports on its Origin, Structure, Commercial Production and Gelling Mechanism. In Polymers for Personal Care Products and Cosmetics; Loh, X. J., Ed.; Royal Society of Chemistry: Cambridge, U.K., 2016; pp 205-226.

(10) Heng, H. Y. J.; Loh, X. J. Antibacterial Polymers. In Polymers for Personal Care Products and Cosmetics; Loh, X. J., Ed.; Royal Society of Chemistry: Cambridge, U.K., 2016; pp 90-107.

(11) Benderly, D.; Zolotarsky, Y. Beyond Thickening - Use of Alkyl Acrylate Crosspolymer in Personal Care Formulations. In Polymers for Personal Care and Cosmetics; ACS Symposium Series; American Chemical Society, 2013; Vol. 1148, pp 205-218.

(12) Lochhead, R. Y. A Review of Recent Advances in the Polymeric Delivery of Attributes in Cosmetics and Personal Care Products. In Polymeric Delivery of Therapeutics; ACS Symposium Series; American Chemical Society, 2010; Vol. 1053, pp 3-22.

(13) Paderes, M.; Ahirwal, D.; Fernández Prieto, S. Natural and Synthetic Polymers in Fabric and Home Care Applications. Physical Sciences Reviews 2017, 2, 1-20.

(14) Abdollahi, H.; Salimi, A.; Barikani, M.; Zeynizadeh, B. New Synthesis Processes of Polyetheramines: Comparison of Three 
Different Developed Amination Routes. Mater. Manuf. Processes 2017, 32, 1296-1303.

(15) Amey, R. L. Polyetheramines, Compositions Including Polyetheramines, and Methods of Making. US8,765,904B2, July 1, 2014.

(16) Klein, H. P.; Burton, B. L.; Forkner, M. W.; Alexander, D. C.; Renken, T. L.; Godinich, C. E. Polyether Polyamine Agents and Mixtures Therefor. US7,550,550B2, June 23, 2009.

(17) Sanchez Garcia, A. M.; Step, E. N.; Sawrey, J. S.; Nguyen, L. H.; Preneta, J. B. Oxidized Carbon Blacks Treated with Polyetheramines and Coating Compositions Comprising Same. US20150087764A1, March 26, 2015.

(18) Flosser, D.; Garcia, P.; Corley, L. S.; Erdem, B.; Lucy, P. Curing Agent for Epoxy Coatings. US20170137664A1, May 18, 2018.

(19) Yao, H.; Hang, J.; Sun, X.; Jin, L.; Shi, L.; Zhang, J. Preparation and Anticorrosive Behavior of Epoxy-Polysiloxane Hybrid Coatings Modified by Polyetheramines. J. Adhes. Sci. Technol. 2014, 28, 11031116.

(20) Jalageri, M. D.; Puttaiahgowda, Y. M.; Parambil, A. M.; Varadavenkatesan, T. Synthesis and Fabrication of Highly Functionalized Jeffamine Antimicrobial Polymeric Coating. Polym. Adv. Technol. 2019, 30, 1616.

(21) Mocanu, G.; Nichifor, M.; Picton, L.; About-Jaudet, E.; Le Cerf, D. Preparation and Characterization of Anionic Pullulan Thermoassociative Nanoparticles for Drug Delivery. Carbohydr. Polym. 2014, $111,892-900$.

(22) Dulong, V.; Mocanu, G.; Picton, L.; Le Cerf, D. Amphiphilic and Thermosensitive Copolymers Based on Pullulan and Jeffamine ${ }^{\circledR}$ : Synthesis, Characterization and Physicochemical Properties. Carbohydr. Polym. 2012, 87, 1522-1531.

(23) Mocanu, G.; Souguir, Z.; Picton, L.; Le Cerf, D. Multiresponsive Carboxymethyl Polysaccharide Crosslinked Hydrogels Containing Jeffamine Side-chains. Carbohydr. Polym. 2012, 89, $578-585$.

(24) Agut, W.; Brûlet, A.; Taton, D.; Lecommandoux, S. Thermoresponsive Micelles from Jeffamine-b-poly(l-glutamic acid) Double Hydrophilic Block Copolymers. Langmuir 2007, 23, 1152611533.

(25) Riachy, P.; Lopez, G.; Emo, M.; Stébé, M.-J.; Blin, J. L.; Ameduri, B. Investigation of a Novel Fluorinated Surfactant-Based System for the Design of Spherical Wormhole-like Mesoporous Silica. J. Colloid Interface Sci. 2017, 487, 310-319.

(26) May-Masnou, A.; Pasc, A.; Stébé, M. J.; Gutiérrez, J. M.; Porras, M.; Blin, J. L. Solubilization of Decane into Gemini Surfactant with a Modified Jeffamine Backbone: Design of Hierarchical Porous Silica. Microporous Mesoporous Mater. 2013, 169, 235-241.

(27) May, A.; Pasc, A.; Stébé, M. J.; Gutiérrez, J. M.; Porras, M.; Blin, J. L. Tailored Jeffamine Molecular Tools for Ordering Mesoporous Silica. Langmuir 2012, 28, 9816-9824.

(28) Vancaeyzeele, C.; Nguyen, G. T. M.; Michan, A. L.; Viallon, M.; Michal, C. A.; Vidal, F. Lithium-based Oligomer Ionic Liquid for Solvent-free Conducting Materials. Polymer 2018, 142, 337-347.

(29) Aldalur, I.; Zhang, H.; Piszcz, M.; Oteo, U.; RodriguezMartinez, L. M.; Shanmukaraj, D.; Rojo, T.; Armand, M. Jeffamine ${ }^{\circledR}$ Based Polymers as Highly Conductive Polymer Electrolytes and Cathode Binder Materials for Battery Application. J. Power Sources 2017, 347, 37-46.

(30) Clarke, T. M. Rheological Properties of Cosmetics and Toiletries. In Cosmetic Science and Technology Series; Laba, D., Ed.; Marcel Dekker, Inc: New York, 1993; Vol. 13, pp 55-152.

(31) Schramm, G. A Practical Approach to Rheology and Rheometry; 2nd ed.; Gebrueder Haake: Karlsruhe, Germany, 1994.

(32) Fernandez-Prieto, S.; Dolatkhani, M.; De Borggraeve, W. M.; Paderes, M. C. Hydrophobically Modified Urea Ethers as Structurants for Hydrophobic Systems. US10092489B2, October 9, 2018.

(33) Kirilov, P.; Le, C. A. K.; Rabehi, H.; Rum, S.; Villa, C.; Haftek, M.; Pirot, F. Organogels for Cosmetic and Dermo-Cosmetic Applications - Classification, Preparation and Characterization of
Organogel Formulations - Part 1, Household Pers. Care Today 2015, 10, 15-19.

(34) Fonnum, G.; Bakke, J.; Hansen, F. K. Associative Thickeners. Part I: Synthesis, Rheology and Aggregation Behavior. Colloid Polym. Sci. 1993, 271, 380-389.

(35) Hammouda, B.; Ho, D. L.; Kline, S. Insight into Clustering in Poly(ethylene oxide) Solutions. Macromolecules 2004, 37, 69326937.

(36) Beaucage, G. Small-Angle Scattering from Polymeric Mass Fractals of Arbitrary Mass-Fractal Dimension. J. Appl. Crystallogr. 1996, 29, 134-146.

(37) Kline, S. R. Reduction and Analysis of SANS and USANS Data Using IGOR Pro. J. Appl. Crystallogr. 2006, 39, 895-900. 